"A comparative study of supports for the synthesis of oligonucleotides without using ammonia." Aviñó, A., Güimil García, R., Díaz, A., Albericio, F., Eritja, R. Nucleosides \& Nucleotides, 15(11-12), 1871-1889 (1996). doi: 10.1080/07328319608002739

\title{
A comparative study of supports for the synthesis of oligonucleotides without using ammonia.
}

\author{
Anna Aviñó ${ }^{1}$, Ramon Güimil García ${ }^{2}$, Antonio Díaz ${ }^{2}$, Fernando \\ Albericio $^{3}$, Ramon Eritja ${ }^{* 1,2}$ \\ ${ }^{1}$ Centro de Investigación y Desarrollo. CSIC. Jordi Girona 18. 08034 \\ Barcelona. Spain. \\ ${ }^{2}$ European Molecular Biology Laboratory, Meyerhofstrasse 1, D-69117 \\ Heidelberg. Germany. \\ ${ }^{3}$ Dpt de Química Orgànica. Universitat de Barcelona. Diagonal 647. 08028 \\ Barcelona. Spain.
}

\begin{abstract}
A comparative study of the cleavage efficiency of succinyl, phthaloyl, oxalyl, 2-(2-nitrophenyl)ethyl, 9-fluorenylmethyl, and 2nitrophenyl supports in $0.5 \mathrm{M}$ DBU solutions is described. A decrease in cleavage efficiency is observed when small oligonucleotides containing thymidine are linked to the supports. In these conditions oxalyl supports gave the best yields followed by 2-(2-nitrophenyl)ethyl and 9fluorenylmethyl supports.
\end{abstract}

Solid-phase oligonucleotide synthesis relies on the use of solid supports in where the first nucleoside is covalently attached to the solid support. In almost all the cases, a 3'-succinate is attached to the support via an amide bond ${ }^{1}$. At the end of the synthesis the oligonucleotide is released with concentrated ammonia together with the rest of the amino and phosphate protecting groups. Recently, the need for modified oligonucleotides carrying ammonia sensitive moieties has led to the development of linkers that could be cleaved under milder conditions such as oxalyl ${ }^{2}, o$-nitrobenzyl $\left.\right|^{3}$ and $o$-nitrophenylethyl $\left.\right|^{4}$ linkers. The oxalyl linker is much more sensitive to bases than conventional nucleoside-succinyl supports, and it is cleaved using diluted solutions of primary and secondary amines. $^{2}$ The $o$-nitrobenzyl linker is cleaved by photolysis and the 0 nitrophenylethyl is cleaved by non-nucleophillic bases $(1,8-$ diazabicyclo[5.4.0] undec-7-ene, DBU). The utility pf these special linkers has been demonstrated during the preparation of oligonucleotides carrying ammonia sensitive molecules such as $O$-methyl-phosphotriesters ${ }^{2}, 5^{\prime}$-fatty ester conjugates ${ }^{5}$, thymine C5-hydrate ${ }^{3 \mathrm{C}} \quad O$-alkylthymidine ${ }^{6} \quad$ 2fluorohypoxanthine ${ }^{6}$ and 5-aza-2'-deoxycytidine. ${ }^{6}$

During the preparation of oligonucleotides using the $O^{-}$ nitrophenylethyl linker the presence of dimethoxytrityl (DMT) groups was still observed on DMT-oligonucleotide-supports after long DBU treatments (16 hrs with $0.5 \mathrm{M}$ DBU in pyridine). ${ }^{6,7}$ This result was surprosong knowing that DMT-nucleosides were released from 0 -nitrophenylethyl supports ysing DBU solutions in less than one hour ${ }^{4 a}$. In the present communication we 
analyze the release of small oligonucleotides from supports having different linkers such as succinyl $\left.\right|^{8,9}$, phthaloyl $^{8}$, oxalyl ${ }^{2}$, o-nitrophenylethyl (NPE) ${ }^{4}, 9$ fluorenylmethyl $(F M)^{10}$ and 0 -nitrobenzyl ${ }^{3}$. Some of these supports have been described to be cleaved by DBU solutions but the cleavage was always measured on DMT-nucleoside supports ${ }^{2,4,8,9}$. No data was available for oligonucleotides linked to the supports.

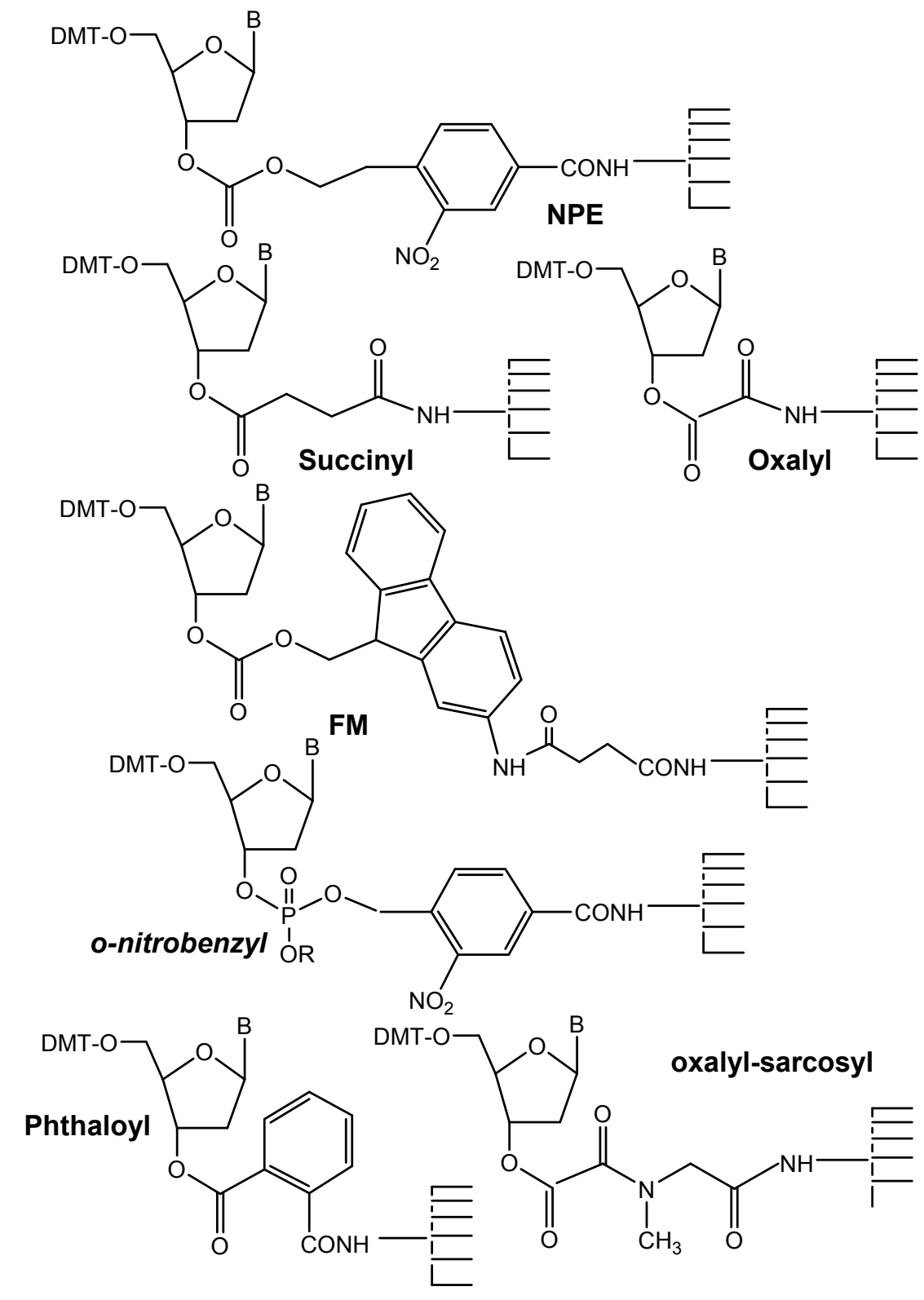

FIGURE 1: Solid supports prepared in this work. DMT stands for dimethoxytrityl-; NPE is o-nitrophenylethyl; FM is fluorenylmethyl; $\mathrm{R}$ is 2cyanoethyl; B is protected A, C, G and T as defined in the text. Supports are prepared starting from long amino alkyl chain-controlled pore glass (LCAACPG, $500 \AA$ ). 


\section{RESULTS AND DISCUSSION}

\section{Stability of the NPE linker to DBU}

DMT-nucleosides protected with the ( $p$-nitrophenyl)ethyl (NPE) and ( $p$-nitrophenyl)ethoxycarbonyl (NPEOC) groups linked to controlled-pors glass (CPG) through a 2-(o-nitrophenyl)ethyl (NPE) linker (FIGURE 1) were prepared as described ${ }^{4}$.

DMT-T-NPE-support was treated with 0.5 M DBU in dry pyridine. At different times the solution was filtered and the cleavage efficiency was measured by the absorbance of the DMT cation in the filtrates compared with the amount DMT cation present on the solid support. The release of DMT-T form NPE support was very fast and quantitative (see FIGURE 2). After 1 min of DBU treatment $60 \%$ of the DMT-T was released and after 10 minutes most of the DMT-T was in the solution (more than $90 \%$ ).

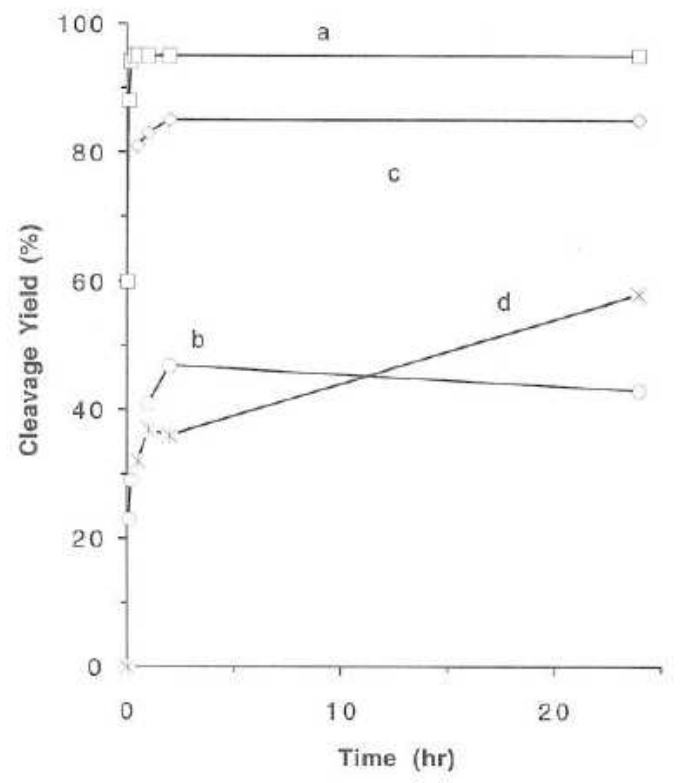

FIGURE 2: Cleavage of NPE supports by $0.5 \mathrm{M}$ DBU in pyridine. A) DMT-TNPE, b) DMT-TT-NPE, c) DMT-A ${ }^{\mathrm{Bz}} \mathrm{A}^{\mathrm{Bz}} \mathrm{A}^{\mathrm{NPEOC}}-\mathrm{NPE}$ and d) DMT-TT-NPE in the presence of thymine.

When DMT-TT-NPE-support was treated with $0.5 \mathrm{M}$ DBU in dry pyridine a different behavior was observed (FIGURE 2). After $1 \mathrm{hr}$ the release of the DMT-TT arrived to a plateau near $50 \%$ cleavage efficiency and decreases slowly to $45 \%$. The same profile was observed using dry dioxane or dry dichloromethane instead of pyridine. Increased temperatures up to 60 degrees did not increase the cleavage efficiency. Keeping the deprotection solution in rigorous anhydrous conditions or in the dark did not increase the yields. Renewing the deprotection solution every 5 minutes was also attempted without any increase of the overall yield. Finally, adding $5 \mathrm{mg}$ of thymine to the deprotection solution gave a different profile (FIGURE 2). At short times, the cleavage efficiency was lower than without tymine. This fact could be due to a decrease on the concentration of the free DBU due to partial protonation caused by thymine. At long term, the cleavage efficiency increased steadily to arrive at $60 \%$ after 16 hours. These results suggested than may be the lower efficiency on the cleavage of 
DMT-TT was due to the formation of some side product on the support during the DBU treatment that was not cleaved by DBU. One hypothesis was based on previous side reactions observed during DBU treatment with the cyanoethyl group used for the protection of the phosphate ${ }^{4 b}$. In this hypothesis the polymeric o-nitrostyrene coming from the breakdown of the NPE carbonate could react with the released DMT-TT via Michael addition to yield a $\mathrm{N}^{1}$-derivative (FIGURE 3 ). Also, nucleophilic attack of the thymine at the $5^{\prime}$-end to the carbonate linker could be possible in the dimer but not at the monomer level (FIGURE 3).

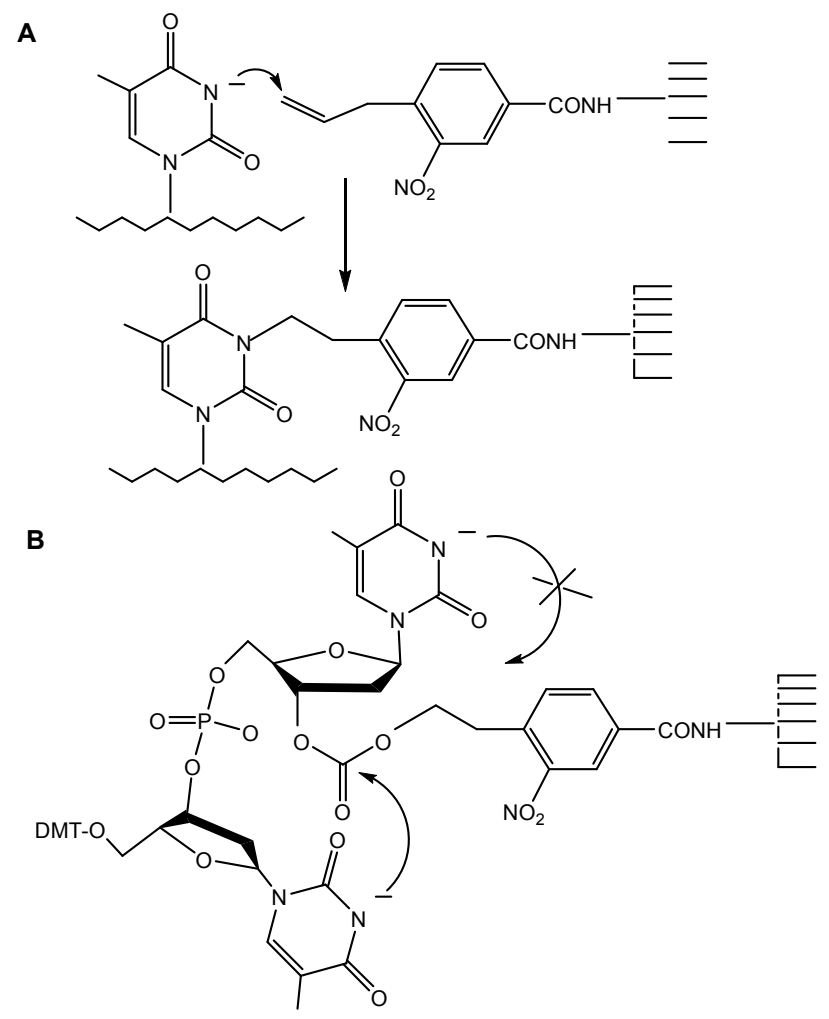

FIGURE 3: Side reactions that could explain the lower efficiency on NPE supports.

To test this hypothesis, DMT- $A^{B z} A^{B z} A^{N P E O C}-N P E$ support was prepared. Michael additions with acrylonitrile formed during the elimination of cyanoethyl phosphate have not been observed in adenine ${ }^{4 \mathrm{~b}}$. Also, protected adenine will not react with the carbonate linker. When this support was treated with $0.5 \mathrm{M} \mathrm{DBU}$, the cleavage efficiency was $85 \%$ in one hour without thymine (FIGURE 2) and a similar result was found after an overnight DBU treatment in the presence of thymine as scavenger ${ }^{4 h}$.

Therefore, the cleavage efficiency on 0 -nitrophenylethyl supports using DBU solutions is sequence-dependent and thymidine-rich oligonucleotides are cleaved less efficiently. The addition of thymine helps to increase the cleavage efficiency probably by competing with the 
oligonucleotide for reactive sites formed during or after the release of the oligonucleotide.

To find a solution to this problem, supports having different linker molecules were prepared and analyzed for their capacity of releasing thymidine-rich oligonucleotides.

\section{Preparation of the succinyl, phthaloyl, FM, oxalyl and o-nitrobenzyl solid supports.}

Supports having succinyl linker were obtained from commercial sources (Cruahem Ltd, Scotland). DMT-T-support having phthaloyl linker was obtained by reaction of DMT-T 3'-O-phthaloate with amino-LCAA-CPG catalyzed by dicyclohexylcarbodiimide (DCC), hydrozybenzotriazole (HOBt) and $\mathrm{N}, \mathrm{N}$-dimethylaminopyridine (DMAP). DMT-T 3'-O-phthaloate was obtained by reaction of DMT-T with phthalic anhydride and DMAP.

The method used for the preparation of the 9-fluorenylmethyl carbonate (FM) solid support was similar to the method described for the preparation of NPE supports ${ }^{4}$ and it had five steps: 1) preparation of methyl ester of the linker, 2) preparation of the choloroformate, 3) formation of the carbonate bond with protected nucleoside, 4) saponification of the methyl ester and 5) incorporation of the nucleoside-linker to the solid support (FIGURE 4). Reaction of $\mathrm{N}$-[9-(hydroxymethyl)-2-fluorenyl] succinamic acid $^{10}$ with methanol and acetyl chloride yielded the methyl ester that was treated with phosgene to produce the corresponding chloroformate. Reaction of DMT-T with the chloroformate in dichloromethane in the presence of 1 eq of DMAP yielded the desired carbonate in $51 \%$ yield after purification, A short treatment of the methyl ester with diluted $\mathrm{NaOH}$ solution yielded the desired FM linker derivative in $50 \%$ yield after isolation. The carboxylic acid derivative was reacted with amino-LCAA-CPG by activation with DCC, HOBt and DMAP. In summary, the method used for the preparation of the NPE linkers ${ }^{4}$ was also useful for the preparation of FM supports although yields with the FM linkers are lower probably due to the increased lability of the FM linker to bases.

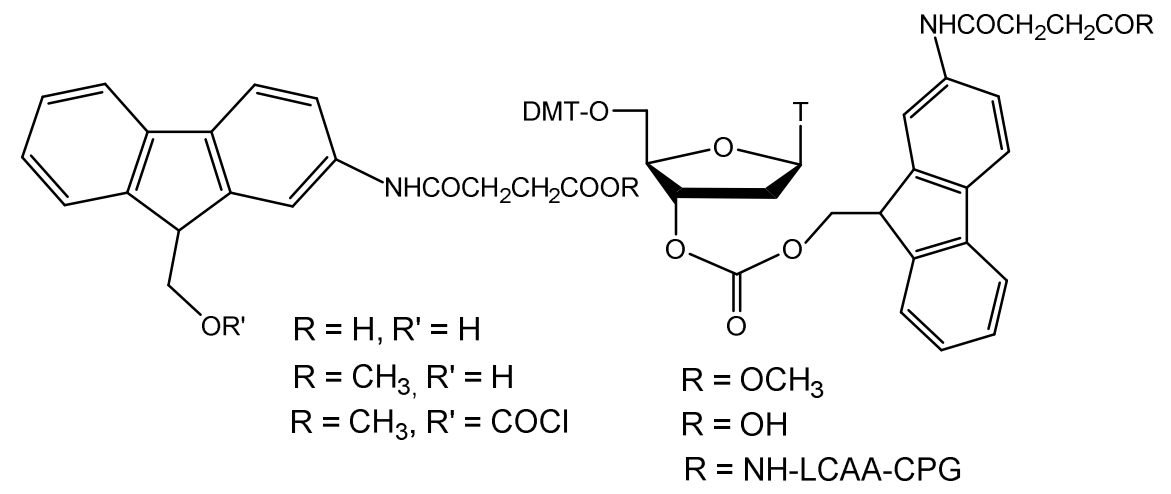

FIGURE 4: Preparation of FM supports.

Supports having the oxalyl linker were prepared as described ${ }^{2}$. Finally, a support having the o-nitrobenzyl group was prepared. 4Hydroxymethyl-3-nitrobenzoic acid $^{11}$ was coupled to amino-LCAA-CPG by activation with DCC and HOBt. The addition of DMT-T phosphoramidite to 
the hydroxymethyl-3-nitrobenzamide support yielded, after oxidation, a photolabile 0 -nitrobenzyl phosphate ${ }^{12}$.

\section{Cleavage of nucleosides and oligonucleotides from the supports with DBU.}

\section{Succinyl supports}

DMT-T-succinyl support was treated with $0.5 \mathrm{M}$ DBU in pyridine. The release of DMT-T was followed by quantitation of the absorbance of the DMT group in acid solutions. The cleavage was much slower than the cleavage of NPE supports: $20 \%$ after 2 hours, $66 \%$ after 6 hours and $76 \%$ after 16 hours.

The treatment of DMT-TT-succinyl support with the DBU solution gave a different profile (FIGUE 5). After 4 hours only $22 \%$ of cleavage was observed and after 16 hours the cleavage efficiency reached $30 \%$. On the other hand, DMT- $\mathrm{A}^{\mathrm{Bz}} \mathrm{A}^{\mathrm{Bz}} \mathrm{A}^{\mathrm{Bz}}$-succinyl support reached a plateau around $75 \%$ cleavage yield after 6 hours. These results indicate that the low efficiency found in the cleavage of T-rich oligonucleotides in NPE supports was also happening on succinyl supports. In this case a nucleophilic attack of the thymine ring to the succinate ester function is laso feasible and may be this causes the lowering on the cleavage efficiency.

\section{Phthaloyl supports}

It has been described that phthaloyl linker is cleaved by DBU more readily than succinyl linker because intramolecular cyclisation is favired because the rigid conformation of the aromatic ring locates the groups involved in the intramolecular attack in close proximity ${ }^{8}$. This was true for the cleavage of DMT-T-phthaloyl support with DBU solutions. In 1.5 hours a $65 \%$ of cleavage was observed. Unfortunately, the cleavage of DMT-TTphthaloyl support in DBU has a similar profile to DMT-TT succinyl support (see FIBURE 5). At the beginning the cleavage was faster with the phthaloyl support but they reach a similar plateau after 4 hours of reaction at $20-30 \%$ yield.

\section{FM support}

Cleavage of DMT-T by treatment of DMT-T-FM support with DBU solutions was very fast. After $10 \mathrm{~min}$ no DMT-T was left on the support. Unfortunately the behavior of DMT-TT-FM support was similar to NPE supports. After 15 minutes the cleavage yield arrived to a plateau near $50 \%$ yield (FIGURE 5).

\section{o-Nitrobenzyl support}

The o-nitrobenzyl phsopahte support was not previously described but supports bearing similar linkages such as o-nitrobenzyl carbonate or ester have been recently described ${ }^{3}$. DMT-T and DMT-TT-o-nitrobenzyl phosphate support were treated with $0.5 \mathrm{M} \mathrm{DBU}$ solution and they were stable to DBU. Only a cleavage of around $20 \%$ was observed after 16 hours. On the contrary, the linker was cleaved with concentrated ammonia ( $85 \%$ after 16 hours treatment with concentrated ammonia at $50{ }^{\circ} \mathrm{C}$ ) and with irradiation with a $350 \mathrm{~nm}$ lamp (60\%, after 6 hours of irradiation with an EYE H125 BL 125 W black-light lamp). 


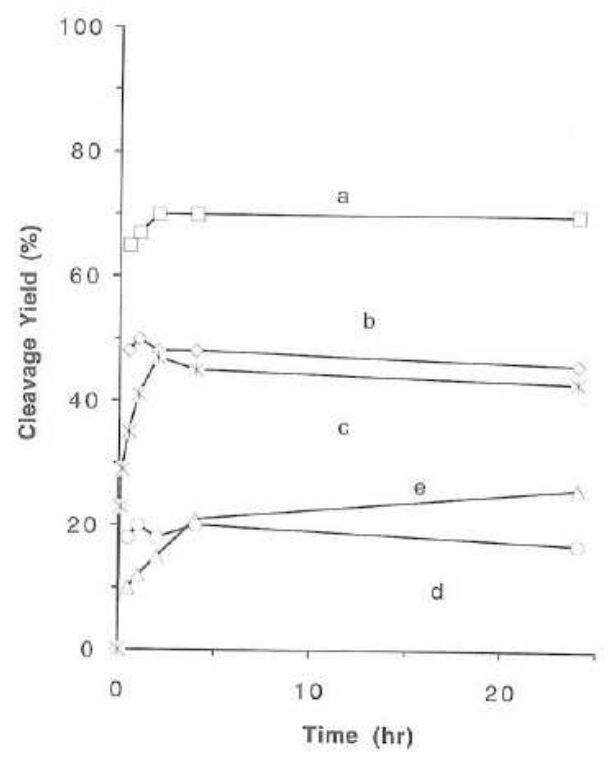

FIGURE 5: Cleavage of DMT-TT from different supports using 0.5 M DBU solution in pyridine. A) oxalyl support; b) FM support; c) NPE support; d) phthaloyl support; e) succinyl support.

\section{Oxalyl support}

It has been described that oxalyl supports are more sensitive to primary and secondary amines than succinyl supports ${ }^{2}$. But, they are stable to tertiary bases such as dry pyridine and triethylamine ${ }^{2}$. The behavior of this linkage in DBU solution was not described. We found that DMT-T oxalyl support was also very labile to DBU solutions. In less than 30 minutes no DMT-T was left on the support. When DMT-TT-oxalyl support was treated with DBU a plateau was reached after 30 minutes near $70 \%$ yield (FIGURE 5 ). This was the highest yield obtained in this study. The addition of thymine to the DBU solution did not affect the cleavage yield.

Two possible pathways could explain the cleavage of DMT-T-oxalyl support. First and similarly to the succinyl linker, the carboxamido group could attack the oxalyl ester. The result of the intramolecular reaction will be DMT-T and a diketoazocyclopropane derivative (FIGURE 6). Also, as described for the 3'-O-mesyl derivatives of thymidine the oxygen of position 2 could attack the $3^{\prime}$-position yielding anhydro-thymidine derivatives ${ }^{13}$. In order to answer this question, the oligonucleotide $5^{\prime}-T T \Pi T T T-3^{\prime}$ was prepared on $1 \mu \mathrm{mol}$ using oxalyl support and DMT-T cyanoethyl phosphoramidite. The oligonucleotide support was treated with 0.5 M DBU in pyridine for 1 hour at room temperature. After removal of pyridine and DBU using a gel filtration column (Sephadex G-10) the oligonucleotide was purified by HPLC. The oligonucleotide was isolated on a $43 \%$ overall (synthesis and purification) yield. Mass spectrometry gave a molecular mass of 2066.6 corresponding to $T_{7}$ (expected 2066.3). Therefore, the formation of anhydro-T at the $3^{\prime}$ end was ruled out.

In order to know if the carboxamido group was implicated in the cleavage of the oxalyl ester, a sarcosine ( $\mathrm{N}$-methylglycine) was incorporated 
between amino-LCAA-CPG and DMT-T-oxalyl linker. It has been described that the incorporation of the sarcosine in the succinyl linkage results in a succinyl support stable to DBU solutions ${ }^{8,9}$. In this case the resulting DMT-Toxalyl-sarcosyl was also labile to DBU reaching a $80 \%$ cleavage yield after 1 hour. In the oxalyl case there is still the possibility of the formation of a sixmembered ring when the carboxamido groups attacks the oxalyl ester function. For this reasona second sarcosine was introduced. The resulting DMT-T-oxalyl-sarcosyl-sarcosyl-LCAA-CPR was more stable to DBU solution. After 1 hour $30 \%$ cleavage was observed that reach a $50 \%$ yield after 3 hours. These results suggest the implication of the carboxamido group in the cleavage of the oxalyl ester.

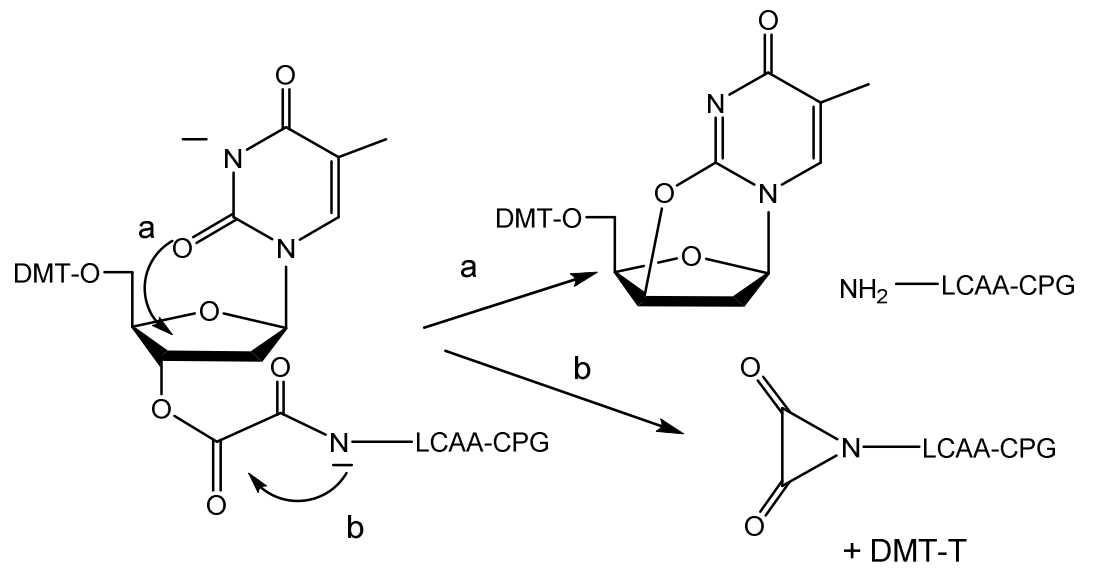

FIGURE 6: Cleavage of DMT-T-oxalyl supports by DBU.

\section{Isolation of the aziridine derivative produced during the DBU cleavage of oxalyl supports.}

The isolation of the aziridine derivative produced by the attack of the carboxamido tp the ester was attempted. For that purpose DMT-O- $\left(\mathrm{CH}_{2}\right)_{6}$ $\mathrm{NH}_{2}$ was reacted with 5'-O-tert-butyldiphenylsilyl thymidine (TBDPS-T), oxalyl chloride and triazol as described for the preparation of oxalylsupports $^{2}$. The resulting oxalyl derivative was isolated and characterized. During the washings with sodium bicarbonatesolution some of the oxalyl derivative underwent to partial decomposition showing the easiness od cleavage of the oxalyl linker (FIGURE 7). Treatment of the oxalyl derivative with DBU yielded two products: 5'-O-tert-butyldiphenylsilyl thymidine and a new DMT-containing product that was different form the starting DMT-O$\left(\mathrm{CH}_{2}\right)_{6}-\mathrm{NH}_{2}$. NMR data were in agreement with the expected 2,3diketoaziridine derivative (one $\mathrm{CO}$ resonance on ${ }^{13} \mathrm{C}-\mathrm{NMR}$ ). Characterization by mass spectrometry was also attempted but the product decomposed without giving the expected molecular mass.

\section{Oligonucleotide synthesis using oxalyl supports.}

Oxalyl supports having $\mathrm{C}^{\mathrm{NPEOC}}, \mathrm{G}^{\mathrm{NPE}, \mathrm{NPEOC}}$, and $\mathrm{A}^{\mathrm{NPEOC}}$ were prepared and they were found also to be cleaved by DBU in short time. Oligonucleotides 5'-TTाTTC-3' and 5'-TTTTTG-3' were prepared on $1 \mu \mathrm{mol}$ scale as described above. Oligonucleotides were isolated on $30-40 \%$ overall yield. Mass spectrometry confirms the expected molecular mass: $\mathrm{T}_{6} \mathrm{C}$ (expected 2052.6, found 2051.2); DMT-T6 $G$ (expected 2394.6 found 
2394.0). Also, oligonucleotides containing 2-fluoro-2'-deoxyinosine have been prepared using DMT-NPE,NPEOC-protected nucleoside NPEphosphoramidites $^{6,7}$ and the appropriate oxalyl supports. Overall yields were $10-30 \%$. Details on the preparation of these modified oligonucleotides will be published elsewhere.

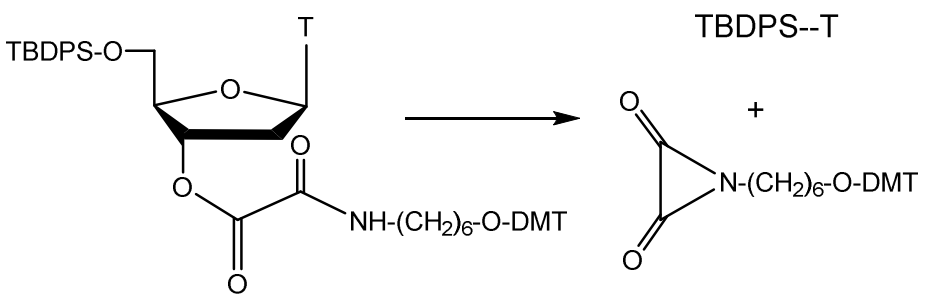

FIGURE 7: Decomposition of an oxalyl model compound with DBU.

Hexamer 5'-GCGATC-3' was prepared on $1 \mu \mathrm{mol}$ scale using DMTNPE,NPEOC-protected nucleoside $\mathrm{H}$-phosphonates ${ }^{7}$ and DMT- $\mathrm{C}^{\text {NPEOC }}$-oxalyl support. The addition of the monomers was done manually using pivaloyl chloride as catalyst. Coupling efficiency was $95 \%$ yield per coupling. At the end of the synthesis, oxidation was performed ${ }^{7}$ and the support was treated with a $0.5 \mathrm{M}$ DBU solution in pyridine containing thymine as scavenger. Purification of oligonucleotide was done by gel filtration (Sephadex G-10) followed by reversed-phase HPLC (DMT on and DMT off) but purified oligonucleotide was isolated in low yields (less than 5\%). Enzyme digestion of the purified oligonucleotide gave the expected ratio of nucleosides. Also, oligonucleotides containing 2-fluoro-2'-deoxyinosine have been prepared using DMT-NPE,NPEOC-protected nucleoside $\mathrm{H}$-phosphonates ${ }^{6,7}$ and oxalyl supports but very low yields have been obtained. The release of oligonucleotides from oxalyl supports was found to by complete by measuring the DMT groups remaining on the support after DBU treatment, but low recoveries of the products were found. Most probably premature cleavage of the oxalyl linkage under the basic condition used during the assembly of the oligonucleotides in the $\mathrm{H}$-phosphonate method could be the reason for the low recoveries.

In summary, we have found that small oligonucleotides containing thymidine are not released efficiently from NOE supports using nonnucleophillic conditions. We have analyzed different linkers and oxalyl supports gave the best results with small oligonucleotides containing thymidine. It should be stressed that oligonucleotidescannot be efficiently released from succinyl supports with DBU solutions. This is a general belief based on previous studies on nucleoside supports ${ }^{2,4,8,9}$ but it turns not to be a general rule for oligonucleotides.

The cleavage of the oxalyl linker by DBU was not previously described, It was found that the release of the oligonucleotide followed the same mechanism described for the succinyl linkerin where the carboxamido group attacks the ester function yielding 3'-OH free oligonucleotideand aziridine derivative. Moreover, the preparation of oxalyl supports was easier than NPE supports. As disadvantage, oxalyl linker was found to be not compatible to $\mathrm{H}$-phosphonate chemistry because oligonucleotides were isolated in very low yields. But, on the other hand oxalyl linker was useful to produce oligonucleotides without using ammonia if NPE, NPEOC protected 
phosphoramidites were used. The results shown here and the easiness of the preparation of oxalyl supports will facilitate the use of the $p$ nitrophenylethyl groups developed by the group of Dr. Pfleiderer ${ }^{14}$ for the preparation of oligonucleotides carrying ammonia sensitive molecules.

\section{EXPERIMENTAL SECTION}

Abbreviations used: $A_{260}$ : absorbance at $260 \mathrm{~nm}, \mathrm{Bz}$ : Benzoyl, CPG: controlled-pore glass, DMAP: 4-(dimethylamino)pyridine, DBU: 1,8diazabicyclo[5.4.0]-undec-7-ene, DCM: dichloromethane, DMF: N,Ndimethylformamidine, DMT: dimethoxytrityl, FM: 9-fluorenylmethyl linker, FMOC: 9-fluorenylmethoxycarbonyl, LCAA: long-chain aminoalkyl, $\mathrm{MeOH}$ : methanol, NPE: $p$-nitrophenylethyl and $o$-(nitrophenyl)ethyl linkage, NPEOC: ( $p$-nitrophenyl)ethoxycarbonyl, TBDPS: t-butyldiphenylsilyl.

DMT- $d A^{\text {NPEOC } 14 c}, D M T-d C^{\text {NPEOC } 14 c}, d G^{\text {NPE,NPEOC 14d }}$, DMT-T-NPE-CPG $(4 c)^{4 b}, N-$ [9-(hydroxymethyl)-2-fluorenyl] succinamic acid ${ }^{10}$ and 4-hydroxymethyl-3nitrobenzoic acid ${ }^{11}$ were prepared following published procedures.

\section{Preparation of DMT-T-phthaloyl support}

Phthaloyl support was prepared as decribed ${ }^{8}$. DMT-T (150 mg, 0.46 $\mathrm{mmol})$ was dissolved in DCM and $102 \mathrm{mg}(0.69 \mathrm{mmol})$ of phthalic anhydride and $84.3(0.69 \mathrm{mmol})$ of DMAP were added. After 16 hours of magnetic stirring at room temperature, the solution was diluted with DCM and washed with $0.1 \mathrm{M} \mathrm{NaH}_{2} \mathrm{PO}_{4}(2 \times 50 \mathrm{ml})$ and saturated $\mathrm{NaCl}$. The organic layer was dried and concentrated to dryness giving $0.31 \mathrm{~g}$ of DMT-T 3'-Ohemiphthaloate $(0.44 \mathrm{mmol})$ that was used without further purification. DMT-T 3'-O-hemiphthaloate $(0.44 \mathrm{mmol})$ was dissolved in DMF and $47.6 \mathrm{mg}$ of HOBt $(0.44 \mathrm{mmol})$ and $92.3 \mathrm{mg}$ of DCC $(0.44 \mathrm{mmol})$ were added and mixture was kept on ice for 10 minutes. The solution is added to $1.8 \mathrm{~g}$ of amino-LCAA-CPG $(0.13 \mathrm{mmol}, 500 \AA$, CPG Inc, New Jersey) together with $53.7 \mathrm{mg}$ of DMAP $(0.44 \mathrm{mmol})$. The mixture was kept at room temperature for 16 hours with occasional mixing. The solid support was filtered and washed with DMF. Unreacted amino groups were blocked by treatment of the support with a $10 \%$ acetic anhydride solution in pyridine for 30 minutes. The resulting support was filtered and washed with acetonitrile and dried. Loading was $15 \mu \mathrm{mol}$ of DMT per gram.

\section{Preparation of DMT-T-FM support}

$\mathrm{N}$-[9-(hydroxymethyl)-2-fluorenyl]succinamic acid ${ }^{10}(250 \mathrm{mg}, 0.8$ $\mathrm{mmol}$ ) was dissolved in $8.6 \mathrm{ml} \mathrm{MeOH}$ and $1.2 \mathrm{ml}$ of acetyl chloride were added. After magnetic stirring for 20 minutes at room temperature the solution was concentrated to dryness. The residue was dissolved in $50 \mathrm{ml}$ of DCM and the solution washed with a saturated sodium carbonate solution $(50 \mathrm{ml})$ and brine $(50 \mathrm{ml})$. The organic layer was dried and concentrated to dryness yielding $250 \mathrm{mg}$ of the methyl ester (96\%). ${ }^{1} \mathrm{H}-\mathrm{NMR}\left(\mathrm{Cl}_{3} \mathrm{CD}, 200\right.$ $\mathrm{MHz}): 7.84(\mathrm{~s}, 1 \mathrm{H}), 7.65(\mathrm{~d}, 2 \mathrm{H}), 7.57(\mathrm{~d}, 2 \mathrm{H}), 7.44-7.31(\mathrm{~m}, 2 \mathrm{H}), 4.05(\mathrm{t}$, $1 \mathrm{H}), 3.71(\mathrm{~m}, 5 \mathrm{H}), 2.74(\mathrm{t}, 2 \mathrm{H}), 2.71(\mathrm{t}, 2 \mathrm{H})$.

$\mathrm{N}$-[9-(hydroxymethyl)-2-fluorenyl]succinamic methyl ester (200 mg) was dissolved in $5 \mathrm{ml}$ of DCM and the solution is added slowly to a $1.9 \mathrm{M}$ phosgene solution in toluene $(2.2 \mathrm{ml})$ cooled with ice. After 1 hour of magnetic stirring at $4{ }^{\circ} \mathrm{C}$ the solution was maintained at room temperature 
for 16 hours. The excess of phosgene was eliminated by applying vacuum with a water aspirator and finally, the remaining solution was concentrated to dryness giving $270 \mathrm{mg}$ of chloroformate as oil (91\% yield) that was used without further purification. ${ }^{1} \mathrm{H}-\mathrm{NMR}\left(\mathrm{Cl}_{3} \mathrm{CD}, 200 \mathrm{MHz}\right): 7.86(\mathrm{~s}, 1 \mathrm{H}), 7.72$ $(\mathrm{d}, 2 \mathrm{H}), 7.68(\mathrm{~d}, 2 \mathrm{H}), 7.59-7.30(\mathrm{~m}, 2 \mathrm{H}), 4.27(\mathrm{t}, 1 \mathrm{H}), 3.73(\mathrm{~s}, 3 \mathrm{H}), 2.77$ $(t, 2 \mathrm{H}), 2.73(\mathrm{t}, 2 \mathrm{H})$.

DMT-T (380 mg, $0.7 \mathrm{mmol}$ ) was dissolved in $20 \mathrm{ml}$ of dry DCM and the solution was cooled with an ice bath. To the solution, $85.5 \mathrm{mg}$ of DMAP $(0.7 \mathrm{mmol})$ and $270 \mathrm{mf}$ of the chloroformate prepared as described above were added. After the addition, the mixture was kept at room temperature for 4 hours. Afterwards, the solution was diluted with $50 \mathrm{ml}$ of DCM and washed with ice-cooled water. The organic phase was dried and concentrated to dryness. The residue was purified on silica gel eluted with a $0-5 \%$ methanol gradient in DCM. Yield $320 \mathrm{mg}(51 \%) .{ }^{1} \mathrm{H}-\mathrm{NMR}\left(\mathrm{Cl}_{3} \mathrm{CD}, 200\right.$ $\mathrm{MHz}): 7.83(\mathrm{~s}, 1 \mathrm{H}), 7.73(\mathrm{~d}, 2 \mathrm{H}), 7.67(\mathrm{~d}, 2 \mathrm{H}), 7.55(\mathrm{~d}, 1 \mathrm{H}), 7.4-7.29(\mathrm{~m}$, $2 \mathrm{H}), 7.27(\mathrm{~m}, 9 \mathrm{H}), 6.83(\mathrm{~d}, 4 \mathrm{H}), 6.48(\mathrm{dd}, 1 \mathrm{H}), 4.5(\mathrm{~m}, 3 \mathrm{H}), 4.24(\mathrm{t}, 1 \mathrm{H})$, $4.18(\mathrm{~m}, 1 \mathrm{H}), 3.78(\mathrm{~s}, 6 \mathrm{H}), 3.73(\mathrm{~s}, 3 \mathrm{H}), 3.47(\mathrm{~d}, 2 \mathrm{H}), 2.74(\mathrm{t}, 2 \mathrm{H}), 2.72(\mathrm{t}$, $2 \mathrm{H}), 2.49(\mathrm{~m}, 1 \mathrm{H}), 1.40(\mathrm{~s}, 3 \mathrm{H})$.

DMT-T-FM-methyl ester $(100 \mathrm{mg}, 0.11 \mathrm{mmol})$ was dissolved in $6.4 \mathrm{ml}$ of dry acetonitrile and $12.5 \mathrm{ml}$ of a $0.05 \mathrm{M} \mathrm{NaOH}$ solution in water / dioxane $(1: 1)$ were added. After 5 minutes of magnetic stirring the solution was neutralized by adding $0.036 \mathrm{ml}$ of acetic acid $(0.62 \mathrm{mmol})$ and concentrated to dryness. The residue was dissolved in $40 \mathrm{ml}$ of DCM and washed with a $10 \%$ citric acid aqueous solution cooled with ice. The organic phase was dried and concentrated to dryness yielding $50 \mathrm{mg}(50 \%)$ of an oil that was used without further purification. ${ }^{1} \mathrm{H}-\mathrm{NMR}$ was similar than the previous compound except that the signal at $3.73 \mathrm{ppm}$ corresponding at the methyl ester was not present anymore.

DMT-T-FM carboxylic acid was linked to amino-LCAA-CPG (500 $\AA$, CPG Inc, New Jersey) as described for the phthaloyl linker. Loading $11 \mu \mathrm{mol}$ per gram).

\section{Preparation and properties of DMT-T-phosphate-o-nitrobenzyl support}

4-Hydroxymethyl-3-nitrobenzoic acid ${ }^{11}(9.4 \mathrm{mg}, 0.05 \mathrm{mmol})$ was dissolved in $2 \mathrm{ml}$ of DMF and HOBt $(6 \mathrm{mg}, 0.05 \mathrm{mmol})$ and DCC (10 mg, 0.05 ) were added. The solution was kept on ice for 10 minutes and added to $250 \mathrm{mg}$ of amino-LCAA-CPG $(0.018 \mathrm{mmol}, 71.3 \mu \mathrm{mol}$ per gram, $500 \AA$, CPG Inc, New Jersey). The mixture was kept at room temperature for 16 hours with occasional mixing. The resin was filtered, washed with DMF and acetonitrile and dried. The support was negative to ninhydrin test.

The hydroxymethyl support was placed on a column and two $1 \mu \mathrm{mol}$ synthesis were performed. In one column one addition of DMT-T cyanoethyl phosphoramidite was performed and a second synthesis with two $T$ additions was performed. Standard $1 \mu \mathrm{mol}$ scale cycles were used. Two aliquots of DMT-TT-o-nitrobenzyl support $(6 \mathrm{mg})$ were mixed with concentrated ammonia overnight at $55^{\circ} \mathrm{C}$. in both cases $80-85 \%$ cleavage yield was found as judged by DMT analysis. Two aliquots of DMT-TT-onitrobenzyl support $(6 \mathrm{mg}$ ) were mixed with $1.5 \mathrm{ml}$ of acetonitrile / water (9:1) and the mixture was irradiated with an EYE H 125 BL125 W black-light lamp for 6 hours. Cleavage yield was $60 \%$ as judged by the analysis of the DMT in the solution and the support. HPLC analysis of the filtrates showed a 
double peak corresponding to the two distereoisomers of the DMT-T- $\left(5^{\prime}-3^{\prime}\right)$ cyanoethyl phosphate-T-cyanoethyl monophosphate. Ammonia treatment followed by removal of DMT resulted one peak that coeluted with TPTp. Aliquots of DMT-T-o-nitrobenzyl support were treated with $0.5 \mathrm{M} \mathrm{DBU}$ in pyridine and the presence of DMT in the filtrates was analyzed. Only $20 \%$ cleavage was found after 16 hours of treatment.

\section{Preparation of oxalyl supports}

Oxalyl supports were prepared essentially as described by Letsinger ${ }^{2}$. The method involves reaction of oxalyl chloride with 4.8 equivalents of 1,2,4-triazole in acetonitrile followed by addition of 1 equivalent DMTprotected nucleoside. After 1 hour the activated monomer is then added to amino-LCAA-CPG (500 $\AA$, CPG Inc, New Jersey) and the mixture is kept at room temperature for 30 minutes. The support is filtered and washed. Unreacted amino groups are blocked with an equivolume mixture of $0.3 \mathrm{M}$ DMAP and $0.6 \mathrm{M}$ acetic anhydride in tetrahydrofuran. The capping solutions used in the DNA synthesizer could not be used because $\mathrm{N}$-methylimidazole cleaves the oxalyl in this step. During the assembly of the oligonucleotide no premature losses of oligonucleotide due to the $\mathrm{N}$-methylimidazole solution were observed. Nucleoside loadings were 20-40 $\mu \mathrm{mol}$ per gram.

DMT-T-oxalyl-sarcosyl and DMT-oxalyl-sarcosyl-sarcosyl-support were prepared by successive additions of FMOC-sarcosine and activated DMT-T-oxalate. For the incorporation of FMOC-sarcosine, the method described by Gupta ${ }^{15}$ was used. In this method carboxylic acid is activated by triphenylphosphine, 2,2'-dithiobis-(5-nitropyridine)and DMAP. After the addition of FMOC- sarcosine, the FMOC group was removed with $20 \%$ piperidine in DMF. The filtrates were collected to quantify the loading (301 $\mathrm{nm}, 7.800)$. The initial loading of the CPG was $140 \mu \mathrm{mol}$ per gram. After the addition of the first FMOC-sarcosine loading was $86 \mu \mathrm{mol}$ per $\mathrm{g}$ and the second addition of FMOC-sarcosine gave a loading of $67 \mu \mathrm{mol}$ per $\mathrm{g}$. The incorporation of activated DMT-oxalate gave the following loadings: DMT-Toxalyl-Sar-CPG $24 \mu \mathrm{mol}$ per g and DMT-T-oxalyl-Sar-Sar-CPG $10 \mu \mathrm{mol}$ per g.

\section{Evaluation of stability of nucleoside and oligonucleotide-supports to DBU}

Approx. $5 \mathrm{mg}$ of the DMT-nucleoside and DMT-oligonucleotidesupports were mixed with $0.5 \mathrm{M}$ DBU solution in pyridine or DCM or dioxane. At different times the supports were filtered and washed with pyridine and acetonitrile. The combined filtrates were concentrated to dryness and $5 \mathrm{ml}$ of $60 \%$ perchloric acid / ethanol (3:2) was added slowly and the absorbance at $500 \mathrm{~nm}$ of the orange solution was measured. On the other hand, the support was treated with $2 \%$ dichloroacetic acid in DCM and filtered until all the orange color is removed from the support. The combined filtrates were concentrated to dryness and the residue was dissolved with $5 \mathrm{ml}$ of $60 \%$ perchloric acid / ethanol (3:2). The absorbance at $500 \mathrm{~nm}$ was measured and added to the value obtained with the filtrates to calculate the percentage of cleavage. Results were shown in FIGURES 2 and 5 in the text.

\section{Oligonucleotide synthesis and purification}


Sequence 5'-GCGATC-3' was prepared using $35 \mathrm{mg}(1 \mu \mathrm{mol})$ of supports DMT-C ${ }^{\text {NPEOC }}$-oxalyl support and Npeoc, Npe protected nucleoside $\mathrm{H}$ phosphonates $^{7}$ on a home-made manual synthesizer. Syntheses were performed using the protocol described by Fröehler et $\mathrm{al}^{16}$ (coupling reagent: pivaloyl chloride). Coupling efficiencies were 95\%. Oxidation of $\mathrm{H}-$ phosphonate polymers was performed as described ${ }^{16}$.

Sequences $T_{7}, T_{6} G, T_{6} C$ were assembled using $35 \mathrm{mg}(1 \mu \mathrm{mol})$ of appropriate oxalyl supports and DMT-T-cyanoethyl phosphoramidite on an automated DNA synthesizer (Applied Biosystems Mod. 392). Standard 1 $\mu \mathrm{mol}$ scale synthesis cycle were used. Coupling efficiencies were higher than $98 \%$.

After the assembly of the sequences the supports were treated with a $0.5 \mathrm{M}$ DBU solution in anhydrous pyridine $(2 \mathrm{ml})$ at room temperature for 1 $\left(T_{7}\right), 4\left(T_{6} C\right)$ and 16 hours (the rest). The deprotection solution for the DBU treatment in sequence GCGATC contained $5 \mathrm{mg}$ of thymine as scavenger ${ }^{7}$. Deprotection solutions were neutralized with a 50\% acetic acid aqueous solution, filtered and the supports were washed with pyridine and water. The combined filtrates were concentrated to dryness. The residues were dissolved in $20 \mathrm{mM}$ triethylammonium acetate buffer and the solutions were desalted on a Sephadex G-10 column. The oligonucleotide containing fractions were analyzed and purified by HPLC. HPLC conditions were as follows: Column: Nucleosil $120 \mathrm{C} 18(200 \times 4 \mathrm{~mm})$, flow rate $1 \mathrm{ml} / \mathrm{min}$, a 20 min gradient from 2 to $25 \%$ acetonitrile over $20 \mathrm{mM}$ aqueous triethylammonium acetate. Overall (synthesis and purification) yields were: GCGATC 5\%, $\mathrm{T}_{7} 43 \%, \mathrm{~T}_{6} \mathrm{G} 20 \%, \mathrm{~T}_{6} \mathrm{C} 15 \%$. Hexamer GCGATC was analyzed by snake venom phosphodiesterase and alkaline phosphatase digestion followed by HPLC analysis ${ }^{17}$. Heptamers were analyzed by mass spectrometry (electrospray) $\mathrm{T}_{7}$ : found 2066.6 expected 2066.3; DMT-T 6 G : found 2394.0 expected 2394.6; $\mathrm{T}_{6} \mathrm{C}$ : found 2051.2 expected 2052.6.

\section{Preparation of 0-DMT-6-amino-1-hexanol}

6-Chloro-1-hexanol (1 $\mathrm{g}, 7.3 \mathrm{mmol})$ was reacted with potassium phthalimide $(1.5 \mathrm{~g}, 8.1 \mathrm{mmol})$ in $50 \mathrm{ml}$ of DMF at $60{ }^{\circ} \mathrm{C}$ for 4 hours as described in ref. 18 giving 6-N-phthaloyl-6-amino-1-hexanol in 71\%. 6-Nphthaloyl-6-amino-1-hexanol $(1 \mathrm{~g}, 4.0 \mathrm{mmol})$ was reacted with DMT-Cl $(1.55 \mathrm{~g}, 4.4 \mathrm{mmol})$ in pyridine as described in ref. 18 yielding $1-\mathrm{O}-\mathrm{DMT}-6-\mathrm{N}-$ phthaloyl-6-amino-1-hexanol in $78 \%$ yield. ${ }^{13} \mathrm{C}-\mathrm{NMR}\left(\mathrm{Cl}_{3} \mathrm{CD}\right): 168.2,158.3$, $145.4,136.7,133.7,132.1,129.9,128.1,127.5,126.4,123.0,112.9$, 85.6, 63.2, 55.0, 37.9, 29.8, 28.4, 26.7, 25.8. DMT-6-N-phthaloyl-6-amino1-hexanol ( $1 \mathrm{~g}, 1.81 \mathrm{mmol}$ ) was dissolved with $80 \mathrm{ml}$ of DCM-MeOH (1:3) and $0.09 \mathrm{ml}$ of hidrazine hydrate was added. After 1 day of magnetic stirring at room temperature, the white precipitate of the phthaloic acid hydrazine was filtered. The solution was concentrated to dryness and the residue was dissolved in $\mathrm{CHCl}_{3}$. The organic solution was washed with $1 \mathrm{M}$ sodium bicarbonate, dried and concentrated to dryness. The product was purified by column chromatography on silica gel eluting with a 10 to $30 \%$ $\mathrm{MeOH}$ gradient in $\mathrm{CHCl}_{3}$ containing a $2 \%$ of tritehylamine. Yield $690 \mathrm{mg}$ (91\%). ${ }^{13} \mathrm{C}-\mathrm{NMR}\left(\mathrm{Cl}_{3} \mathrm{CD}\right): 158.3,145.3,136.7,129.9,128.1,127.5,126.4$, $112.9,85.6,63.2,55.0,41.4,32.2,29.9,26.6,26.0$.

\section{Preparation of 5'-0-TBDPS-thymidine}


Thymidine $(0.48 \mathrm{~g}, 2 \mathrm{mmol})$ was dissolved in $10 \mathrm{ml}$ of pyridine and the solution was cooled with an ice-bath. To this cooled solution $0.57 \mathrm{ml}$ $(2.2 \mathrm{mmol})$ of $t$-butyldiphenylsilyl chloride were added dropwise. After the addition the reaction mixture was stirred overnight at room temperature. The reaction was stopped by the addition of $10 \mathrm{ml}$ of ethanol and the mixture was concentrated to dryness. The residue was dissolved in $\mathrm{CHCl}_{3}$ and the solution was washed with $1 \mathrm{M}$ sodium bicarbonate, dried and concentrated to dryness. The residual oil was purified by column chromatography on silica gel eluting with a 0 to $5 \% \mathrm{MeOH}$ gradient in $\mathrm{CHCl}_{3}$. Yield: $0.86 \mathrm{~g}(89 \%) .{ }^{13} \mathrm{C}-\mathrm{NMR}\left(\mathrm{Cl}_{3} \mathrm{CD}\right): 164.1,150.7,135.5,135.3$, 133.0, 132.5, 130.0, 129.9, 127.9, 111.1, 87.2, 84.8, 72.0, 64.2, 40.9, $26.9,19.3,11.9$.

\section{Preparation of $\mathrm{N}$-(O-6-DMT-6-hydroxyhexyl) oxamic acid 5'-0- TBDPS-thymidinyl-3'.ester}

$1,2,4$-Triazole ( $345 \mathrm{mg}, 5 \mathrm{mmol}$ ) was dissolved in $8 \mathrm{ml}$ of acetonitrile and $0.8 \mathrm{ml}$ of pyridine. To this solution $0.086 \mathrm{ml}(1 \mathrm{mmol})$ of oxalyl chloride were added. After 10 minutes of magnetic stirring $529 \mathrm{mg}(1.1 \mathrm{mmol})$ of TBDPS-T dissolved in $8 \mathrm{ml}$ of acetonitrile and $4 \mathrm{ml}$ of pyridine were added dropwise and the solution was stirred at room temperature for 1 hour. To the resulting mixture $320 \mathrm{mg}(0.76 \mathrm{mmol})$ of $1-0-\mathrm{DMT}-6$-amino-1-hexanol dissolved in acetonitrile-pyridine (1:1) were added. After 20 minutes of magnetic stirring, the total conversion of the starting DMT-aminohexanol $\left(R_{f}=0.1\right)$ to a new DMT containing product $\left(R_{f}=1\right)$ was observed by TLC ( $20 \%$ ethanol in DCM). The reaction mixture was concentrated to dryness and the residue was dissolved in $\mathrm{CHCl}_{3}$. The chloroform solution was washed with $1 \mathrm{M} \mathrm{NaHCO}$, dried and concentrated to dryness. At this time TLC analysis ( $5 \%$ ethanol in DCM) of the mixture showed two new DMT containing products $\left(R_{f}=0.85\right.$ and 0.38$)$ and a DMT negative product that had the same retention time than TBDPS-T $\left(R_{f}=0.25\right)$. Separation of the products was achieved by column chromatography on silica gel eluting with a $0-15 \% \mathrm{MeOH}$ gradient in $\mathrm{CHCl}_{3}$.

Product $1\left(R_{\mathrm{f}}=0.85\right.$, DMT positive), yield $100 \mathrm{mg}(0.21 \mathrm{mmol}, 28 \%)$, was assigned to N-(0-6-DMT-6-hydroxyhexyl)-2,3-diketoaziridine, It was formed during the sodium bicarbonate washing step. ${ }^{1} \mathrm{H}-\mathrm{NMR}\left(\mathrm{Cl}_{3} \mathrm{CD}\right)$ : 7.4$7.1(\mathrm{~m}, 9 \mathrm{H}), 6.9$ (two d, 4H) $3.8(\mathrm{~s}, 6 \mathrm{H}), 3.26(\mathrm{~m}, 2 \mathrm{H}, 3.03(\mathrm{~m}, 2 \mathrm{H}), 1.56$ $(\mathrm{m}, 4 \mathrm{H}) .{ }^{13} \mathrm{C}-\mathrm{NMR}\left(\mathrm{Cl}_{3} \mathrm{CD}\right): 159.9$ (CO) $, 158.4,145.4,136.7,130.0,129.1$, 128.2, 127.8, 127.6, 126.5, 113.0, 85.7, 63.2, 55.1, 39.6, 29.9, 29.1, $26.7,25.9$. IR $\left(\mathrm{cm}^{-1}\right): 1684$ (CO st). MS $\left(\mathrm{FAB}^{+}\right): 405.2\left({ }^{+} \mathrm{CH}_{2}-\left(\mathrm{CH}_{2}\right)_{5}-\mathrm{O}-\right.$ DMT), (laser-desorption) $303\left(\mathrm{DMT}^{+}\right)$.

Product $2\left(R_{f}=0.38\right.$, DMT positive), yield $130 \mathrm{mg}(0.14 \mathrm{mmol}, 18 \%)$, was assigned to the desired oxamic acid derivative. ${ }^{1} \mathrm{H}-\mathrm{NMR}\left(\mathrm{Cl}_{3} \mathrm{CD}\right): 8.83$ (wide $\mathrm{s}, 1 \mathrm{H}), 7.6-7.3(\mathrm{~m}, 20 \mathrm{H}), 6.89(\mathrm{~d}, 4 \mathrm{H}), 6.82(\mathrm{~d}, 4 \mathrm{H}), 6.45(\mathrm{dd}, 1 \mathrm{H})$, $5.54(\mathrm{~m}, 1 \mathrm{H}), 4.22(\mathrm{~m}, 1 \mathrm{H}), 4.0(\mathrm{~m}, 2 \mathrm{H}), 3.79(\mathrm{~s}, 6 \mathrm{H}), 3.32(\mathrm{~m}, 2 \mathrm{H}), 3.6$ $(\mathrm{m}, 2 \mathrm{H}), 2.61(\mathrm{~m}, 1 \mathrm{H}), 2.47(\mathrm{~m}, 1 \mathrm{H}), 1.60(\mathrm{~m}, 7 \mathrm{H}), 1.37(\mathrm{~m}, 4 \mathrm{H}), 1.11(\mathrm{~s}$, 9H). ${ }^{13} \mathrm{C}-\mathrm{NMR}\left(\mathrm{Cl}_{3} \mathrm{CD}\right): 163.7$ (C4 thy), 160.3 (CO oxalyl ester), 158.3 (DMT), 155.6 (CO oxamic), 150.3 (C2 thy), 145.3, 136.6, 135.4, 135.1, 134.6, 133.0, 132.4, 129.9, 128.1, 127.9, 127.5, 126.4, 112.9, 11.3, 85.6, 84.3, 84.3, 77.1 (under $\mathrm{CDCl}_{3}$ signal), 63.7, 63.1, 55.0, 39.6, 37.7, 29.8, 28.9, 26.9, 26.6, 25.8, 19.2, 11.9. IR $\left(\mathrm{cm}^{-1}\right): 1699,1609$. 
Product $3\left(R_{f}=0.25\right.$, DMT negative), yield $370 \mathrm{mg}(0.77 \mathrm{mmol}, 70 \%$ of starting material), had the same NMR and TLC characteristics than starting TBDPS-T.

Treatment of product 2 with $0.5 \mathrm{M} \mathrm{DBU}$ solution in acetonitrile yielded products 1 and 3 that were isolated and characterized.

\section{ACKNOWLEDGEMENTS}

We are grateful to CICYT (PB92-0043) and E.E.C.C. Biomedicine and Health Programme (BMH1-CT93-1669) for financial support. We thank Drs. Matthias Mann, Gitte Neubauer, Matthias Wilm (EMBL) and Irene Fernández (University of Barcelona) for obtaining mass spectra.

\section{REFERENCES}

1. Caruthers, M.H., Barone, A.D., Beaucage, S.L., Dodds, D.R., Fisher, E.F., McBride, L.J., Matteucci, M., Stabinsky, Z., and Tang, J.Y., Meth. Enz., 1987, 154, 287-313.

2. Alul, R.H., Singman, C.N., Zhang, G.R., and Letsinger, R.L. Nucleic Acids Res., 1991, 19, 1527-1532.

3. a) Greenberg, M.M. Tetrahedron Lett., 1993, 34, 251-254; b) Green berg, M.M. and Gilmore, J.L. J. Org. Chem., 1994, 59, 746-753; c) Matray, T.J., Haxton, K.J. and Greenberg, M.M. Nucleic Acids Res., 1995, 23, 46424648; d) Greenberg, M.M. Tetrahedron 1995, 51, 29-38; and e) Venkatesan, H. and Greenberg, M.M. J. Org. Chem., 1996, 61, 525-529.

4. a) Eritja, R., Robles, J., Fernández-Forner, D., Albericio, F., Giralt, E., and Pedroso, E. Tetrahedron Lett., 1991, 32, 1511-1514 and b) Eritja, R., Robles, J., Aviñó, A., Albericio, F., and Pedroso, E. Tetrahedron, 1992, 48, 4171-4182.

5. Polushin, N.N., and Cohen, J.S. Nucleic Acids Res., 1994, 22, 54925496.

6. Aviñó, A., Güimil-Garcia, R., Marquez, V.E., and Eritja, R. Bioorg. Med. Chem. Lett., 1995, 5, 2331-2336.

7. Aviñó, A., and Eritja, R. Nucleosides \& Nucleotides, 1994, 13, 20592069.

8. Brown, T., Pritchard, C.E., Turner, G., and Salisbury, S.A. J. Chem. Soc. Chem. Commun., 1989, 891-893.

9. Stengele, K., and Pfleiderer, W., Tetrahedron Lett., 1990, 31, 25492552.

10. Rabanal, F., Giralt, E., and Albericio, F. Tetrahedron Lett., 1994, 35, 1775-1778.

11. Lloyd-Williams, P., Gairí, M., Albericio, F., and Giralt, E. Tetrahedron, 1991, 47, 9867.

12. Pillai, V.R.N. Synthesis 1980, 1-26.

13. Glinski, R.P., Khan, M.S., Kalamas, R.L., and Sporn, M.B. J. Org. Chem., 1973, 38, 4299-4305.

14. a) Pfleiderer, W., Schwarz, M. and Schirmeister, H. Chemica Scr., 1986, 26, 147-154, b) Pfleiderer, W., Himmelsbach, F., Charubala, R., Schirmeister, H., Beiter, A., Schulz, B., and Trichtinger, T. Nucleosides \& Nucleotides, 1985, 4, 81-94, c) Himmelsbach, F., Schulz, B., Trichtinger, T., Charubala, R., and Pfleiderer, W. Tetrahedron, 1984, 40, 59-72 and d) 
Schirmeister, H., Himmelsbach, F., and Pfleiderer, W. Helv. Chim. Acta, 1993, 76, 385-401.

15. Gupta, K.C., Kumar, P., Bhathia, D., and Sharma, A.K. Nucleosides \& Nucleotides, 1995, 14, 829-832.

16. Froehler, B., Ng, P., and Matteucci. M. Nucleic Acids Res., 1986, 14, 5399-5407.

17. Fernandez-Forner, D., Palom, Y., Ikuta, S., Pedroso, E., and Eritja, R. Nucleic Acids Res., 1990, 18, 5729-5734.

18. Aviñó, A., Güimil-Garcia, R., Albericio, F., Mann, M., Wilm, M., Neubauer, G., and Eritja, R. Biorg. Med. Chem., 1996, 4, 1649-1658. 